\title{
Development of a power electronics converter dynamics toolbox for MATLAB
}

\author{
Farzin Asadi $1, *$, Nurettin Abut ${ }^{2}$, Uzeyir Akca ${ }^{3}$ \\ ${ }_{1}^{1}$ Mechatronics Engineering Department, Kocaeli University, Kocaeli, Turkey \\ ${ }^{2}$ Electrical Engineering Department, Kocaeli University, Kocaeli, Turkey \\ ${ }^{3}$ Kocaeli Vocational School, Kocaeli University, Kocaeli, Turkey
}

\section{A R T ICLE IN F O}

\section{Article history:}

Received 20 December 2016

Received in revised form

25 April 2017

Accepted 3 May 2017

Keywords:

Continuous conduction mode

Converter modeling

Converter dynamic toolbox

Small signal model

State space averaging

\begin{abstract}
A B S T R A C T
Providing the required load's power using Switch Mode Power Supplies (SMPS), leads to smaller and more efficient converters. Correct operation of a SMPS needs some form of control. Applying the well-known controller design techniques like root locus and Bode needs a dynamical model for system under control. Power electronics converters are dynamical variable structure systems. Extraction of small signal dynamical equations by hand is cumbersome, time consuming and error prone. Development a software to automate the small signal model extraction process of power electronics converters is the aim of this paper. Parameter's change and uncertainty's effects on overall system performance can be studied easily using this software. Multi graph property of developed software, allow drawing results of different simulations on the same graph. This makes comparison possible. Available commercial softwares cannot calculate the algebraic transfer functions while developed software can do this job. Contact correspondence author to receive the software.
\end{abstract}

(c) 2017 The Authors. Published by IASE. This is an open access article under the CC BY-NC-ND license (http://creativecommons.org/licenses/by-nc-nd/4.0/).

\section{Introduction}

Power electronics is the science and art of control and efficient conversion of electric power using solid state semiconductor devices. Power range can vary from miliwatts up to several megawatts. Switch Mode Power Supply (SMPS) is among the most common technologies in use. SMPS's working principle is based on storing energy temporarily in passive elements like inductors and capacitors and releasing it to output at different voltage level. SMPS are composed of two parts, i.e., power and control circuitry.

Power circuitry, is responsible for providing required and suitable form of power for load. Control circuitry, provides control signals required for power circuitry's switches, i.e. signals which make the switches on and off. When a switch is made on (off), a new current path is added to (removed from) circuit. In fact, SMPS is an example of variable structure systems. Fig. 1 shows a buck converter and its equivalent circuit for switch is closed and opened.

\footnotetext{
* Corresponding Author.

Email Address: farzin.asadi@kocaeli.edu.tr (F. Asadi) https://doi.org/10.21833/ijaas.2017.06.008

2313-626X/C) 2017 The Authors. Published by IASE.

This is an open access article under the CC BY-NC-ND license

(http://creativecommons.org/licenses/by-nc-nd/4.0/)
}

In order to obtain a dynamical model of variable structure systems, averaging techniques which takes average of sub circuit's state space model has been suggested (Middlebrook and Cuk, 1976). Obtaining a dynamical model for plant is the first step toward designing a controller in model base controller design techniques like Bode diagram and root locus. In this paper a MATLAB ${ }^{\circledR}$ base toolbox is designed to extract converter's dynamical model. Available commercial softwares give only converter's frequency response diagram, while developed software can give either frequency response diagram or the algebraic transfer function. Effect of uncertainties in system parameters can be studied easily with the aid of this toolbox. Developed toolbox can analyze buck, boost, buck-boost, Cuk, SEPIC, fly back, forward and full bridge topologies.

\section{Previous works}

Modeling is the process of formulating a mathematical description of the system. Generally speaking, a dynamical system can be described in two forms, i.e., input-output equation, and state space equation.

Input-output equation gives no information about the internal details of system. State space 
equation, gives more information about internal dynamics of system of system.

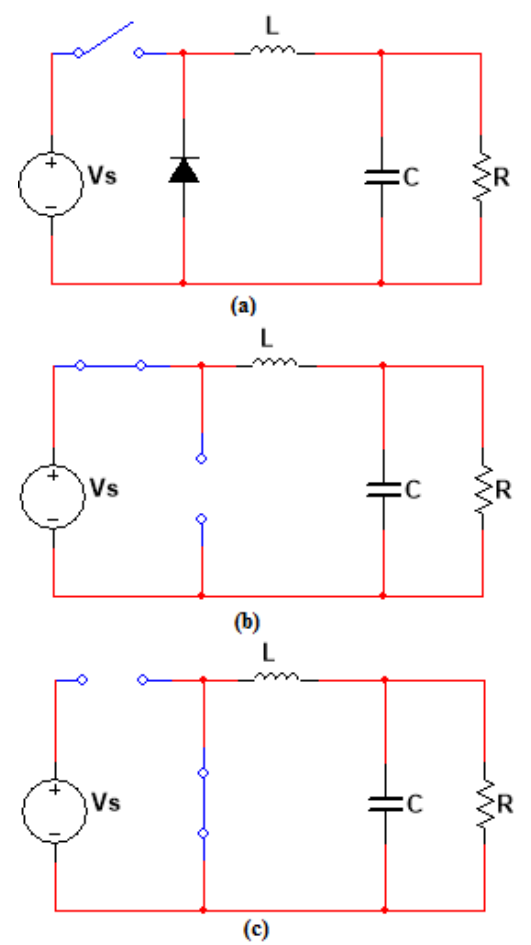

Fig. 1: Buck converter, equivalent circuit for switch close and switch open are shown in $\mathrm{b}$ and c respectively

Various techniques can be found in literature to obtain a linear continuous time invariant (LTI) model of a DC-DC converter. The most well-known methods are: Current injected approach, circuit averaging and state space averaging (Middlebrook and Cuk, 1976; Sokal et al., 1991; Mohan et al., 2007; Vorperian, 1990). Averaging and small signal linearization is key steps of these methods.

State space averaging described in Middlebrook and Cuk (1976) is appropriate to describe converters that work in CCM while is less suitable for converters work in DCM. The current injected method (Sokal et al., 1991; Mohan et al., 2007) can do the job of modeling in either CCM or DCM. Circuit averaging gained a lot of attention recently due to its generality (Hren and Slibar, 2005).

To avoid time and financial losses converter's performance must be ensured before realization. This job can be done with the aid of simulation softwares. Some of the most important softwares are: PSpice ${ }^{\circledR}$, NI Multisim ${ }^{\circledR}$, PSIM $^{\circledR}$, SABER $^{\circledR}$ and
MATLAB ${ }^{\circledR} /$ Simulink $^{\circledR}$. PSpice and NI Multisim are general purpose circuit simulation's programs. Either analogue or digital simulations can be done. Although PSIM can be used to simulate any electronic circuits, it is designed specifically for use in power electronics and motor drive simulations. SABER is a nonlinear dynamic system simulation program. Dynamical equation of power electronics converters is nonlinear in nature. So, after extraction of circuit's dynamical equations SABER can be used to solve these equations. Simulink and power system toolbox of MATLAB provide an environment to analyze power electronics circuits by drawing the schematic (Asadi and Abut, 2016). MATLAB/Simulink can be used to extract small signal Bode plot of converters. It gives no information about system's poles and zero locations. In other words, converter's transfer function can't obtained in closed algebraic form

$H(s)=k \frac{s^{m}+b_{m-1} s^{m-1}+\cdots+b_{0}}{s^{n}+a_{n-1} s^{n-1}+\cdots+a_{0}}$

at the time of this writing, there is no power electronics converter dynamic toolbox available for MATLAB.

There is a rich literature on converter modeling. Here is a quick review of some of them: Mahery et al., (2012) proposed a new method based on Laplace and $\mathrm{Z}$ transforms for mathematical modeling of buck-boost in CCM. Ghadimi et al. (2007) presented a detailed small signal and transient analysis of a full bridge pulse width modulator (PWM) converter based on average model. Emadi (2004) presented a modular approach for modeling based on generalized state space averaging. Modabbernia et al. (2013) presented a complete state space averaging model for buck-boost converter.

\section{CCM, DCM, and state space averaging (SSA)}

SMPS is nothing more than passive elements, semiconductor switches and a controller. In steady state, converters voltages and currents are periodic. An inductor current that remains positive throughout the switching period is known as continuous current. Conversely, in discontinuous current, inductor current's return to zero during each switching period. Table 1, compares two modes of operation:

Table 1: Comparison of CCM and DCM

\section{Continuous Current Mode(CCM)}

- Voltage gain is independent of load

- Input current is continuous and nonpulsating

- Efficiency is higher in comparison with DCM

\section{Discontinuous Current Mode(DCM)}

- Voltage gain is a function of load and design parameters

- Input current is pulsating

- Commutation of controlled switch is made with zero current which reduce commutation losses

- Inductor size can be reduced considerably in comparison with CCM
Generally a CCM converter is designed when the load isn't variable. A variable load may cause converter to enter DCM for light loads. So, this must be taken into account for controller design. Assuming that converter works in CCM next step is to find converter's dynamical equation. 
The two set of state equations: one set for switch close and one set for switch open, are averaged over the switching period. Variables are perturbed around their steady state operating point and small signal dynamical model is extracted.

Assume a general state space model of following form for a CCM converter:

Eqs. 1 and 2, are written under switch close and switch open condition, respectively.

$\left\{\begin{array}{c}\dot{\mathrm{x}}=\mathrm{A}_{1} \mathrm{x}+\mathrm{B}_{1} \mathrm{u} \\ \mathrm{vo}=\mathrm{C}_{1}{ }^{\mathrm{T}} \mathrm{x}\end{array}\right.$
$\left\{\begin{array}{c}\dot{\mathrm{x}}=\mathrm{A}_{2} \mathrm{x}+\mathrm{B}_{2} \mathrm{u} \\ \mathrm{vo}=\mathrm{C}_{2}{ }^{\mathrm{T}} \mathrm{x}\end{array}\right.$

Where $x$ is state vector, i.e. capacitors' voltage and inductors' current, $u$ is control input and $v_{o}$ is output voltage of converter. Applying State Space
Averaging (SSA) to Eqs. 1 and 2 leads to: (Erickson and Maksimovic, 2001):

$\tilde{\mathrm{x}}=\left[\mathrm{A}_{1} \mathrm{D}+\mathrm{A}_{2}(1-\mathrm{D})\right] \tilde{\mathrm{x}}+\left[\left(\mathrm{A}_{1}-\mathrm{A}_{2}\right) \mathrm{X}+\left(\mathrm{B}_{1}-\mathrm{B}_{2}\right) \mathrm{V}\right] \tilde{\mathrm{d}}$

$\tilde{\mathrm{v}}_{\mathrm{o}}=\left[\mathrm{C}^{\mathrm{T}}{ }_{1}+\mathrm{C}^{\mathrm{T}}{ }_{2}(1-\mathrm{D})\right] \tilde{\mathrm{x}}+\left[\left(\mathrm{C}_{1}{ }^{\mathrm{T}}-\mathrm{C}_{2}{ }^{\mathrm{T}}\right) \mathrm{X}\right] \tilde{\mathrm{d}}$

where tilde $\left(\tilde{x}, \tilde{d}, \tilde{v}_{o}\right)$ shows small signal variables and $\mathrm{D}$ shows steady state duty ratio.

Table A in appendix, shows state space of Eqs. 1 and 2 for different type of DC-DC converters. Equations in Table B and Eqs. 3 and 4 make the working principles of developed software.

\section{Designed software}

Fig. 2 shows the main menu of software. Figs. 3, 4, and 5 , show some sections of developed software.

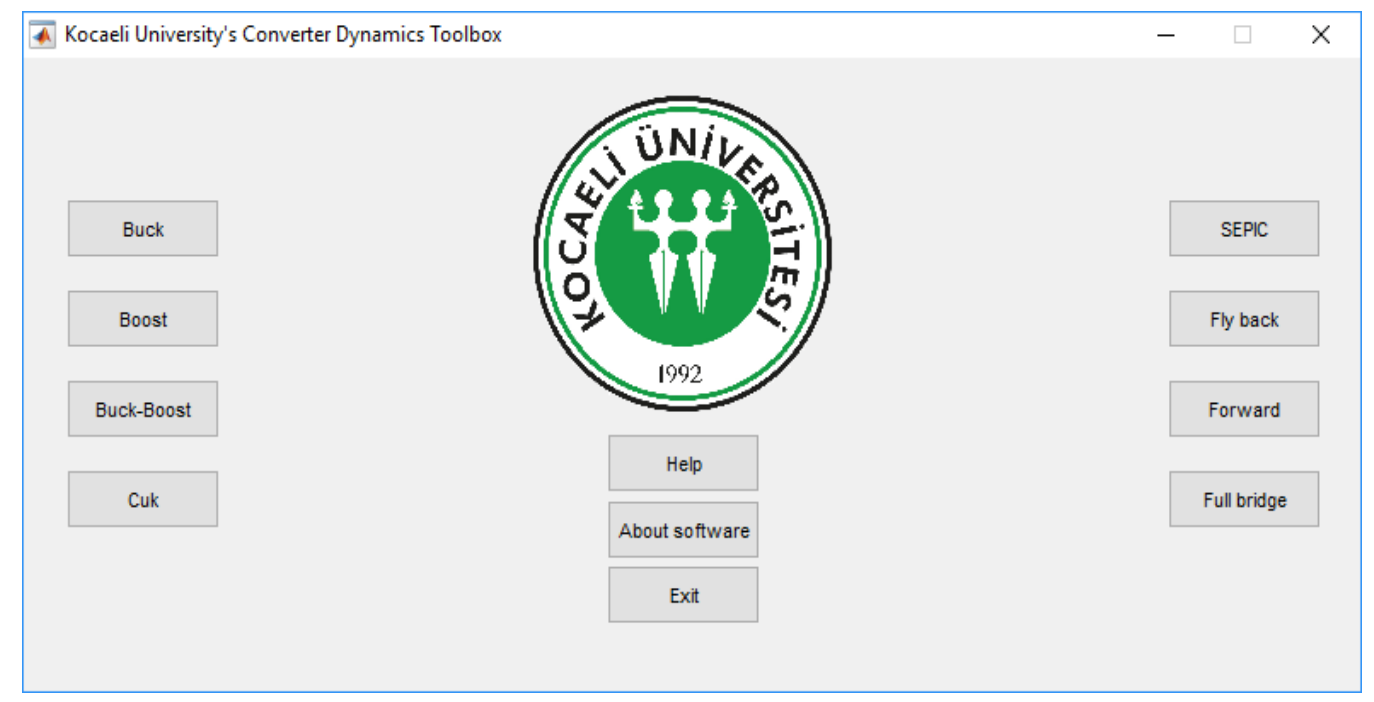

Fig. 2: Main menu of software

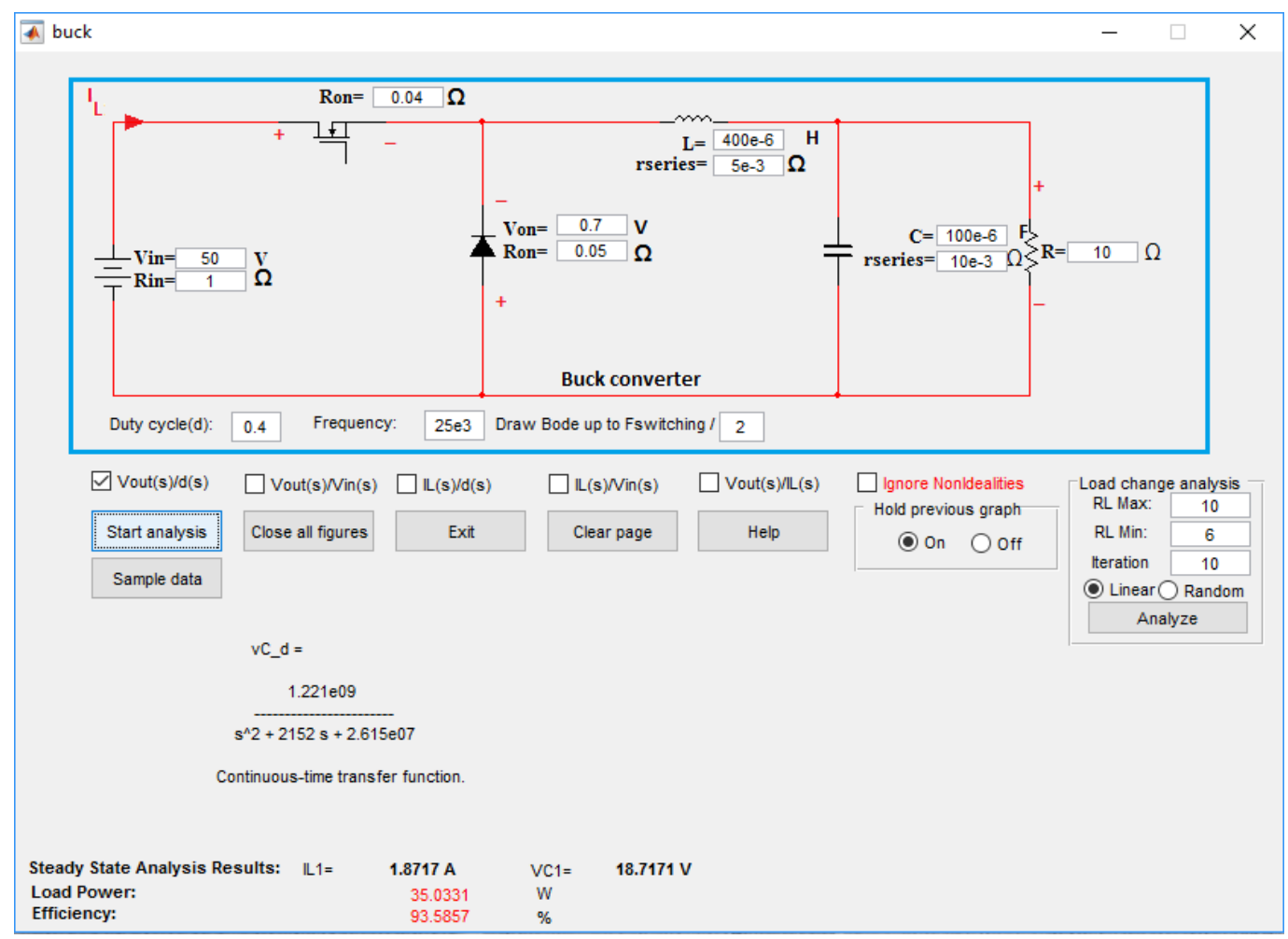

Fig. 3: Buck converter analysis section of software 


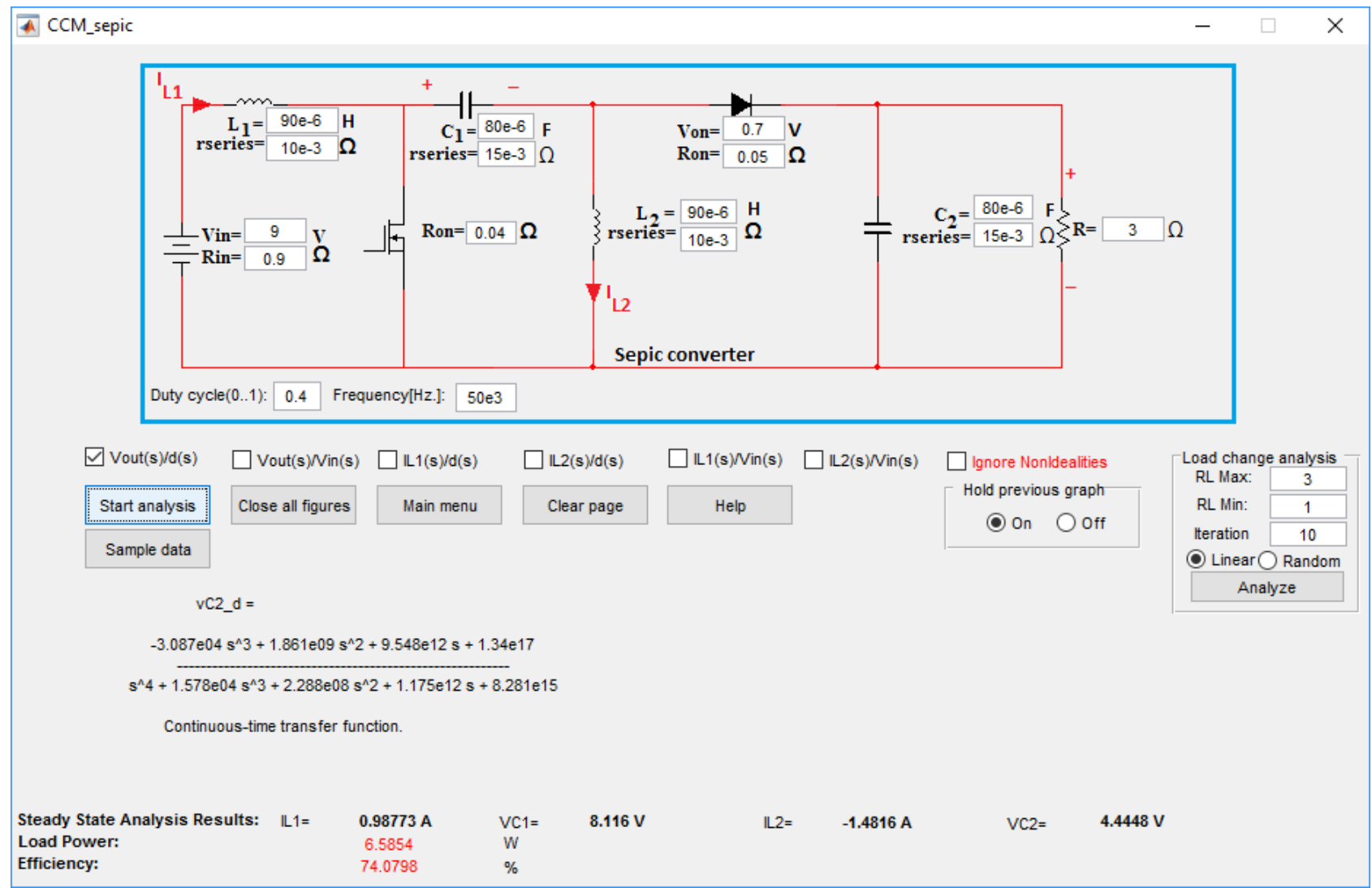

Fig. 4: SEPIC converter analysis section of software

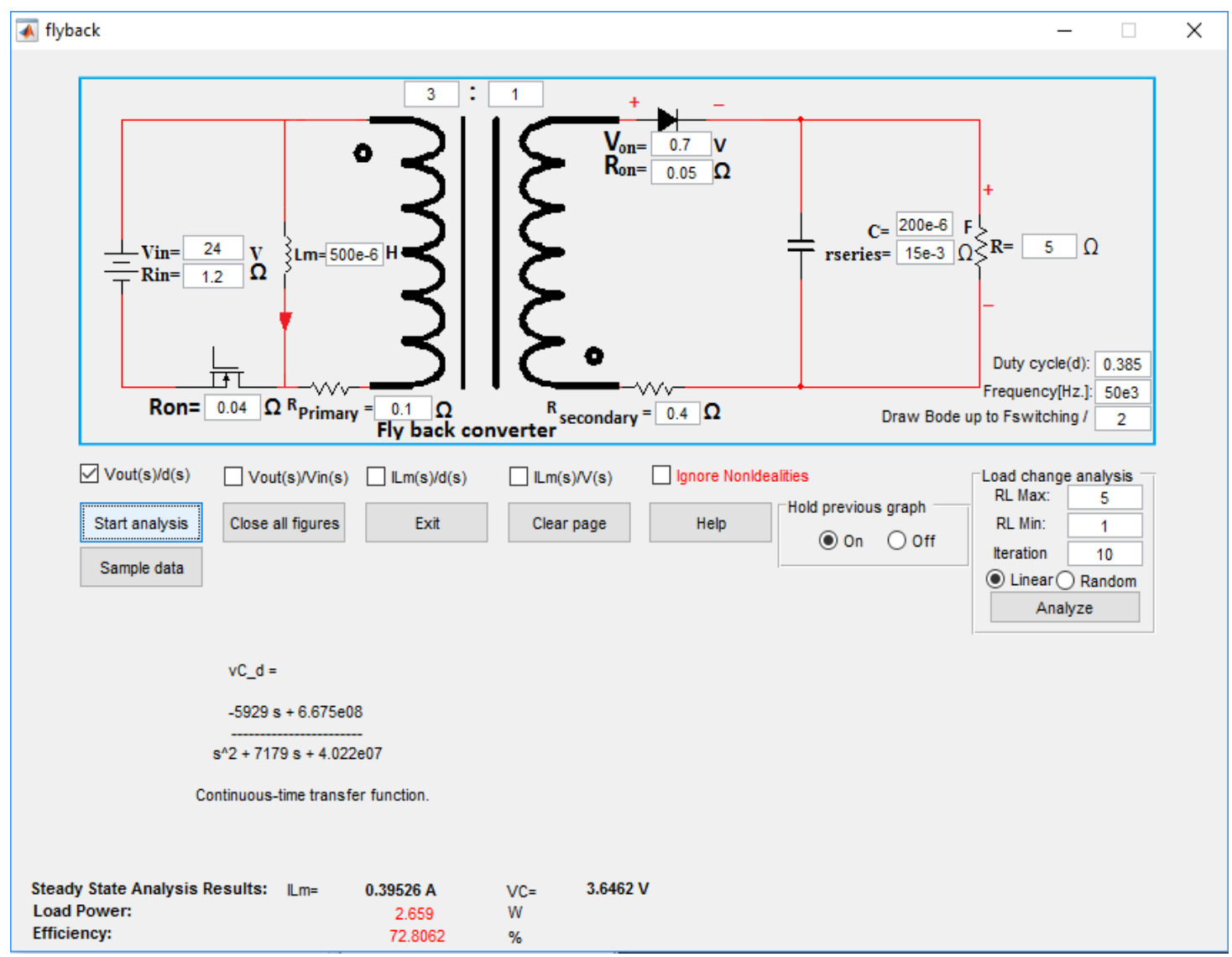

Fig. 5: Fly back converter analysis section of software

Determining the parameters of the circuit is all what must be done by user. There is no need to draw circuit's schematic. Non idealities like equivalent series resistance of inductors and capacitors, voltage drop of diodes, on resistance of MOSFET's and internal resistance of input sources are taken into account. 
Obtaining the dynamical model of converter in presence of these non-idealities is quite cumbersome for pencil-and-paper analysis. Assume a SEPIC converter with the following parameters:

Vin $=9 \mathrm{~V}$, rinternal $=0.9 \Omega, \mathrm{L} 1=\mathrm{L} 2=90 \mu \mathrm{H}, \mathrm{rL} 1=\mathrm{rL} 2=$ $10 \mathrm{~m} \Omega, \mathrm{C} 1=\mathrm{C} 2=80 \mu \mathrm{F}, \mathrm{rC} 1=\mathrm{rC} 2=15 \mathrm{~m} \Omega$, VDiode_on $=$ 0.7 , rDiode_on $=0.05 \Omega$, rMOSFET $=40 \mathrm{~m} \Omega$, RLoad $=3 \Omega$

After entering component's values and selecting the desired transfer function (for example $H(s)=$ $\frac{v_{c 2(s)}}{d(s)}$ ), following results are obtained in Fig. 6.
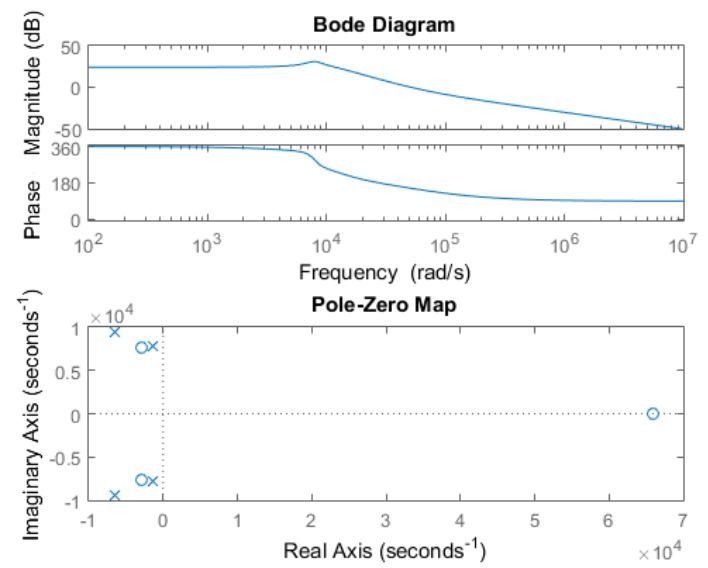

Fig. 6: Bode diagram and pole zero diagram of selected transfer function
Effect of load change on $\frac{\tilde{v}_{c 2}}{\tilde{d}(s)}$ transfer function, i.e. transfer function from control input to output voltage is shown in Fig. 7.

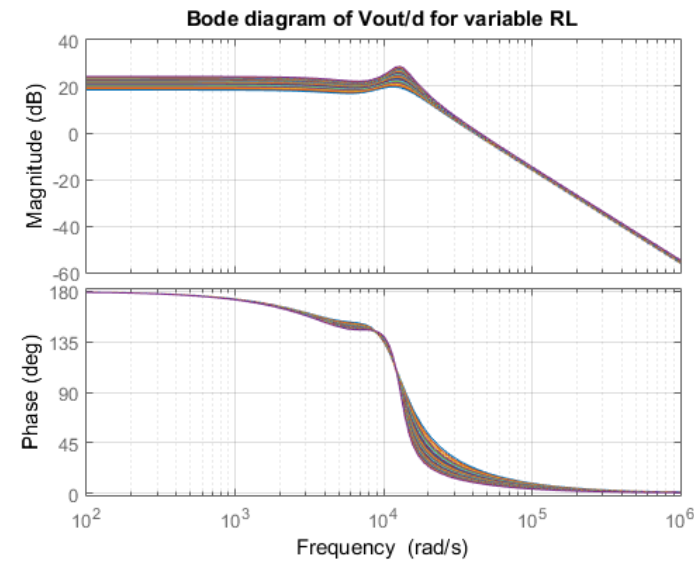

Fig. 7: Effect of load's change on converter's transfer function

Beside this Graphical user interface (GUI), a collection of text base programs are developed to analyze converters symbolically in presence of components non idealities such as diode's voltage drop and capacitor's ESR.

Table 2 shows some of the obtained results for basic converters:

Table 2: Steady state values in presence of component's non-idealities

\begin{tabular}{|c|c|c|}
\hline Topology & Steady state inductor's current & Steady state capacitor's voltage \\
\hline Buck & $\frac{V_{S}+V_{G}(D-1)}{R_{L}+r_{D}+r_{L}+r_{1}-2 \times R_{L} \times D-D \times r_{D}+D \times r_{s w}+R_{L} \times D^{2}}$ & $\frac{R_{L} \times(D-1) \times\left(V_{S}+V_{G} \times(D-1)\right)}{R_{L}+r_{D}+r_{L}+r_{1}-2 \times R_{L} \times D-D \times r_{D}+D \times r_{S w}+R_{L} \times D^{2}}$ \\
\hline Boost & $\frac{V_{S}+V_{G}(D-1)}{R_{L}+r_{D}+r_{L}+r_{1}-2 \times R_{L} \times D-D \times r_{D}+D \times r_{s w}+R_{L} \times D^{2}}$ & $\frac{R_{L} \times(D-1) \times\left(V_{s}+V_{G} \times(D-1)\right)}{R_{L}+r_{D}+r_{L}+r_{1}-2 \times R_{L} \times D-D \times r_{D}+D \times r_{s w}+R_{L} \times D^{2}}$ \\
\hline $\begin{array}{l}\text { Buck- } \\
\text { Boost }\end{array}$ & $\frac{V_{s}+V_{G}(D-1)}{R_{L}+r_{C}+r_{D}+r_{L}-2 \times R_{L} \times D-D \times r_{C}-D \times r_{D}+D \times r_{1}+D \times r_{s w}+R_{L} \times D^{2}}$ & $\frac{R_{L} \times(D-1) \times\left(V_{S} \times D+(1-D) \times V_{G}\right)}{R_{L}+r_{C}+r_{D}+r_{L}-2 \times R_{L} \times D-D \times r_{C}-D \times r_{D}+D \times r_{1}+D \times r_{s w}+R_{L} \times D^{2}}$ \\
\hline
\end{tabular}

\section{Conclusion}

Computers play an important role in designing and analyzing modern power electronics converters. In this paper software has developed to extract small signal dynamical model of famous DC-DC topologies. Developed software can give the algebraic transfer function of converter which makes it different from available commercial softwares. Developed software can be used to design the control loop of converters.

\section{List of symbols}

$\begin{array}{cl}i & \text { current } \\ v & \text { voltage } \\ i_{L j} & \text { j'th inductor current } \\ v_{C j} & \text { j'th capacitor voltage } \\ i_{L m} & \text { magnetizing inductance } \\ & \text { current } \\ N_{1} & \text { primary turns number of } \\ & \text { transformer } \\ N_{2} & \text { secondary turns number of } \\ r_{N 1}, r_{p r i} & \text { transformer } \\ r_{N 2}, r_{\text {sec }} & \text { primary winding's resistance } \\ R_{L} & \text { load resistor value } \\ L & \text { inductor value } \\ C & \text { capacitor value }\end{array}$

$\begin{array}{cl}r_{L}\left(r_{C}\right) & \begin{array}{l}\text { series resistance of inductor } \\ \text { (capacitor) } \\ \text { diode's forward bias series } \\ \text { resistance } \\ r_{D}\end{array} \\ v_{\gamma} & \text { diode's forward voltage drop } \\ r_{s w} & \text { MOSFET's on resistance } \\ r_{i} & \text { input source's internal } \\ V_{S} & \text { resistance } \\ \text { input source's voltage }\end{array}$

\section{References}

Asadi F and Abut N (2016). KUCA: Kocaeli University Converter Analysis simulation software in power electronics. International Journal of Advanced and Applied Sciences, 3(12): 55-61

Emadi A (2004). Modeling and analysis of multiconverter DC power electronic systems using the generalized state-space averaging method. IEEE Transactions on Industrial Electronics, 51(3): 661-668.

Erickson R and Maksimovic D (2001). Fundamental of power electronics. 2nd Edition, Kluwer Academic Publishers, New Jersey, USA.

Ghadimi AA, Rastegar H, and Keyhani A (2007). Development of average model for control of a full bridge pwm dc-dc converter. Journal of Iranian Association of Electrical and Electronics Engineers, 4(2): 52-59.

Hren A and Slibar P (2005). Full order dynamic model of SEPIC converter. In the IEEE International Conference on Industrial 
Electronics (ISIE'05), IEEE, Dubrovnik, Croatia, 2: 553-558. https://doi.org/10.1109/ISIE.2005.1528977

Mahery HM, Torabzad S, Sabahi M, and Babaei E (2012). Modeling and stability analysis of buck-boost dc-dc converter based on Z-transform. In the IEEE $5^{\text {th }}$ India International Conference on Power Electronics (IICPE), IEEE: 1-6. https://doi.org/ 10.1109/IICPE.2012.6450405

Middlebrook R and Cuk S (1976). A general unified approach to modeling switching converter power stages. In the IEEE Power Electronics Specialists Conference, IEEE: 19-34. https://doi.org/10.1109/PESC.1976.7072895

Modabbernia M, Kohani F, Fouladi R, and Nejati S (2013). The state space average model of buck-boost switching regulator including all of the system uncertainties. International Journal on Computer Science and Engineering (IJCSE), 5(2): 120-132.

Mohan N, Undeland T, and Robbins W (2007). Power electronics devices, converters applications and design. John Wiley and Sons, New York, USA.

Sokal NO, Redl R, and Kislovski AS (1991). Dynamic analysis of switching mode dc-dc converter. Van Nostrand Reinhold, New York, USA.

Vorperian V (1990). Simplified analysis of PWM converters using the model of the PWM switch: Parts I and II. IEEE Transactions on Aerospace and Electronic Systems, 26(3): 490-505.

\section{Appendix}

Table A: Different type of DC-DC converters and their large signal state space model

\begin{tabular}{|c|c|c|}
\hline $\begin{array}{c}\text { Converter } \\
\text { type }\end{array}$ & Dynamical equation for switch closed & Dynamical equation for switch opened \\
\hline Boost & $\begin{array}{l}\frac{d}{d t} i_{L}=-\frac{1}{L}\left(r_{L}+r_{C}+r_{D}\right) i_{L}-\frac{1}{L} v_{C}-\frac{1}{L} v_{\gamma} \\
\frac{d}{d t} v_{C}=\frac{1}{C}\left(i_{L}\right)-\frac{1}{R_{L} \times C} v_{C} \\
\frac{d}{d t} i_{L}=-\frac{1}{L}\left(r_{i}+r_{s w}+r_{L}\right) i_{L}+\frac{1}{L} v_{s} \\
\frac{d}{d t} v_{C}=-\frac{1}{R_{L} \times C} v_{C}\end{array}$ & $\begin{array}{l}\frac{d}{d t} i_{L}=-\frac{1}{L}\left(r_{i}+r_{s w}+r_{L}+r_{C}\right) i_{L}-\frac{1}{L} v_{C}+\frac{1}{L} v_{s} \\
\frac{d}{d t} v_{C}=-\frac{1}{C}\left(i_{L}\right)-\frac{1}{R_{L} \times C} v_{C} \\
\frac{d}{d t} i_{L}=-\frac{1}{L}\left(r_{i}+r_{L}+r_{D}\right) i_{L}-\frac{1}{L} v_{C}+\frac{1}{L} v_{s}-\frac{1}{L} v_{\gamma} \\
\frac{d}{d t} v_{C}=\frac{1}{C}\left(i_{L}\right)-\frac{1}{R_{L} \times C} v_{C}\end{array}$ \\
\hline $\begin{array}{l}\text { Buck- } \\
\text { Boost }\end{array}$ & $\begin{aligned} \frac{d}{d t} i_{L} & =-\frac{1}{L}\left(r_{i}+r_{s w}+r_{L}\right) i_{L}+\frac{1}{L} v_{s} \\
\frac{d}{d t} v_{C} & =-\frac{1}{R_{L} \times C} v_{C}\end{aligned}$ & $\begin{array}{l}\frac{d}{d t} i_{L}=-\frac{1}{L}\left(r_{C}+r_{L}+r_{D}\right) i_{L}+\frac{1}{L} v_{C}-\frac{1}{L} v_{\gamma} \\
\frac{d}{d t} v_{C}=-\frac{1}{C}\left(i_{L}\right)-\frac{1}{R_{L} \times C} v_{C}\end{array}$ \\
\hline Cuk & $\begin{array}{l}\frac{d}{d t} i_{L 1}=-\frac{1}{L_{1}}\left(r_{i}+r_{L 1}+r_{s w}\right) i_{L 1}+\frac{r_{s w}}{L_{1}} i_{L 2}+\frac{1}{L_{1}} v_{s} \\
\frac{d}{d t} i_{L 2}=\frac{r_{s w}}{L_{2}} i_{L 1}-\frac{r_{C 1}+r_{L 2}+r_{s w}}{L_{2}} i_{L 2}-\frac{1}{L_{2}} v_{C 1}-\frac{1}{L_{2}} v_{C 2} \\
\frac{d}{d t} v_{C 1}=-\frac{1}{C_{1}} i_{L 2} \\
\frac{d}{d t} v_{C 2}=\frac{1}{C_{2}} i_{L 2}-\frac{1}{R_{L} \times C_{2}} v_{C 2}\end{array}$ & $\begin{aligned} \frac{d}{d t} i_{L 1} & =-\frac{1}{L_{1}}\left(r_{D}+r_{i}+r_{L 1}+r_{C 1}\right) i_{L 1}+\frac{r_{D}}{L_{1}} i_{L 2}-\frac{1}{L_{1}} v_{C 1}+\frac{1}{L_{1}} v_{s}-\frac{1}{L_{1}} v_{\gamma} \\
\frac{d}{d t} i_{L 2} & =\frac{r_{D}}{L_{2}} i_{L 1}-\frac{r_{D}+r_{L 2}+r_{C 2}}{L_{2}} i_{L 2}-\frac{1}{L_{2}} v_{C 2}+\frac{1}{L_{2}} v_{\gamma} \\
\frac{d}{d t} v_{C 1} & =\frac{1}{C_{1}} i_{L 1} \\
\frac{d}{d t} v_{C 2} & =\frac{1}{C_{2}} i_{L 2}-\frac{1}{R_{L} \times C_{2}} v_{C 2}\end{aligned}$ \\
\hline SEPIC & $\begin{array}{l}\frac{d}{d t} i_{L 1}=-\frac{1}{L_{1}}\left(r_{i}+r_{L 1}+r_{s w}\right) i_{L 1}+\frac{r_{s w}}{L_{1}} i_{L 2}+\frac{1}{L_{1}} v_{s} \\
\frac{d}{d t} i_{L 2}=\frac{r_{s w}}{L_{2}} i_{L 1}-\frac{r_{C 1}+r_{L 2}+r_{s w}}{L_{2}} i_{L 2}-\frac{1}{L_{2}} v_{C 1} \\
\frac{d}{d t} v_{C 1}=\frac{1}{C_{1}} i_{L 2} \\
\frac{d}{d t} v_{C 2}=-\frac{1}{R_{L} \times C_{2}} v_{C 2}\end{array}$ & $\begin{array}{l}\frac{d}{d t} i_{L 1}=-\frac{1}{L_{1}}\left(r_{D}+r_{i}+r_{L 1}+r_{C 1}+r_{C 2}\right) i_{L 1}+\frac{r_{C 2}+r_{D}}{L_{1}} i_{L 2}-\frac{1}{L_{1}} v_{C 1}-\frac{1}{L_{1}} v_{C 1}-\frac{1}{L_{1}} v_{\gamma} \\
\frac{d}{d t} i_{L 2}=\frac{r_{D}+r_{C 2}}{L_{2}} i_{L 1}-\frac{r_{D}+r_{L 2}+r_{C 2}}{L_{2}} i_{L 2}+\frac{1}{L_{2}} v_{C 2}+\frac{1}{L_{2}} v_{\gamma} \\
\frac{d}{d t} v_{C 1}=\frac{1}{C_{1}} i_{L 1} \\
\frac{d}{d t} v_{C 2}=\frac{1}{C_{2}} i_{L 1}-\frac{1}{C_{2}} i_{L 2}-\frac{1}{R_{L} \times C_{2}} v_{C 2}\end{array}$ \\
\hline Fly back & $\begin{aligned} \frac{d}{d t} i_{L_{m}} & =-\frac{1}{L_{m}}\left(r_{i}+r_{p r i}+r_{s w}\right) i_{L_{m}}+\frac{1}{L_{m}} v_{s} \\
\frac{d}{d t} v_{C} & =-\frac{1}{R_{L} \times C} v_{C}\end{aligned}$ & $\begin{array}{l}\frac{d}{d t} i_{L_{m}}=-\frac{N_{1}{ }^{2}}{N_{2}{ }^{2} \times L_{m}}\left(r_{C}+r_{s e c}+r_{D}\right) i_{L_{m}}-\frac{N_{1}}{N_{2} \times L_{m}} v_{C}-\frac{N_{1}}{N_{2} \times L_{m}} v_{\gamma} \\
\frac{d}{d t} v_{C}=\frac{1}{C}\left(i_{L_{m}}-\frac{1}{R_{L}} v_{C}\right)\end{array}$ \\
\hline Forward & $\begin{array}{ll} & \left.+\left(\frac{N_{1}}{N_{2}}\right)^{2} r_{C}\right) i_{L}-\frac{1}{L} v_{C}+\frac{1}{L} v_{s} \\
& -\frac{1}{L_{1}} v_{\gamma} \\
d & 1\end{array}$ & $\begin{array}{l}\frac{d}{d t} i_{L}=-\frac{1}{L} \times\left(r_{C}+r_{D}+r_{L}\right) i_{L}-\frac{1}{L} v_{C}-\frac{1}{L_{1}} v_{\gamma} \\
\frac{d}{d t} v_{C}=\frac{1}{C} i_{L}-\frac{1}{R_{L} \times C} v_{C}\end{array}$ \\
\hline $\begin{array}{c}\text { Full } \\
\text { Bridge }\end{array}$ & $\begin{array}{c}\overline{d t} l_{L}=-\bar{L}\left(r_{C}+R_{T}\right) l_{L}-\bar{L} v_{C}+\bar{L} v_{s}-\bar{L} v_{\gamma} \\
\frac{d}{d t} v_{C}=-\frac{1}{C}\left(i_{L}\right)-\frac{1}{R_{L} \times C} v_{C} \\
\text { where } R_{T}=\left(\frac{N_{s e c}}{N_{p r i}}\right)^{2} \times\left(r_{i}+2 \times r_{s w}+r_{p r i}\right)+r_{s e c}+ \\
r_{D}+r_{L}\end{array}$ & $\begin{array}{l}\frac{d}{d t} i_{L}=-\frac{1}{L}\left(r_{C}+R_{T}\right) i_{L}-\frac{1}{L} v_{C}+\frac{1}{L} v_{s}-\frac{1}{L} v_{\gamma} \\
\frac{d}{d t} v_{C}=-\frac{1}{C}\left(i_{L}\right)-\frac{1}{R_{L} \times C} v_{C}\end{array}$ \\
\hline
\end{tabular}


Table B: Schematic of DC-DC converters (Equivalent series resistance of inductors and capacitors are not shown)

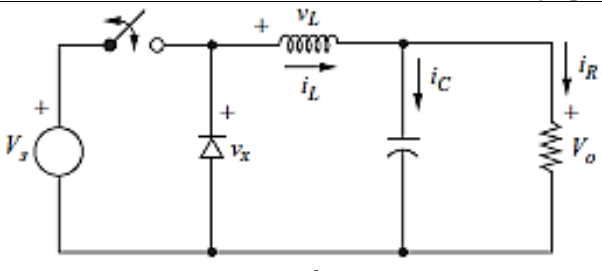

Buck

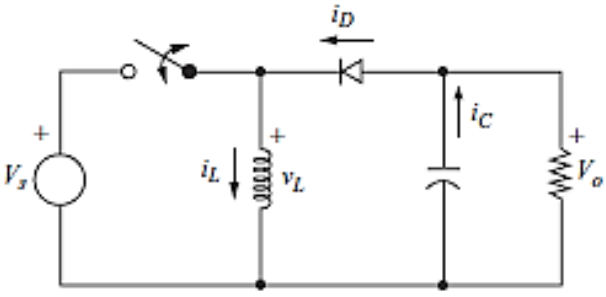

Buck-Boost

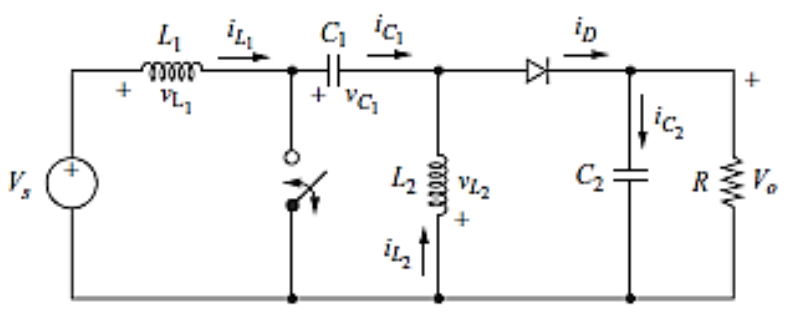

SEPIC

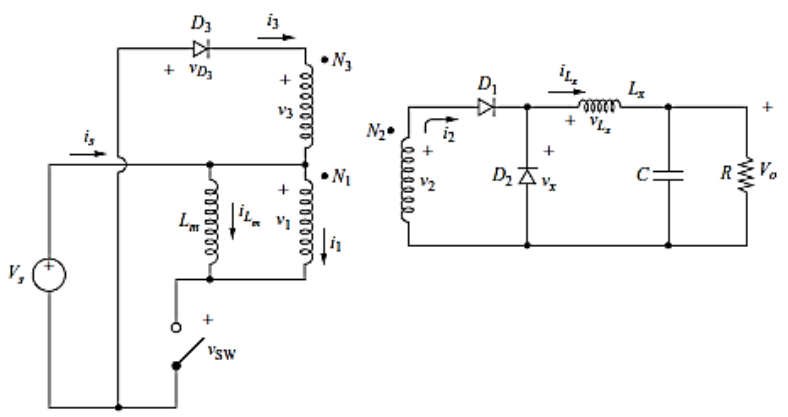

Forward
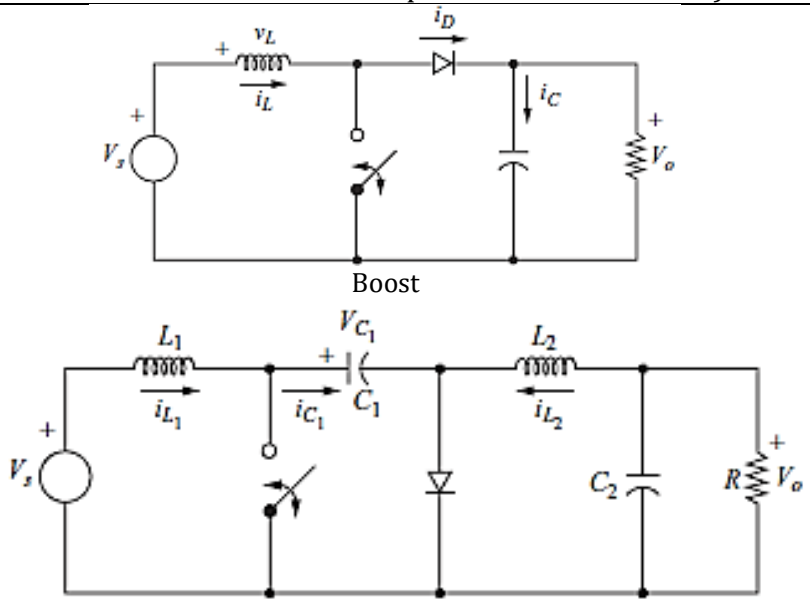

Cuk

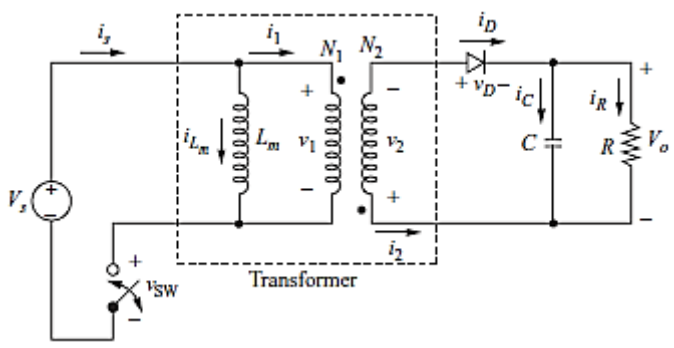

Fly back

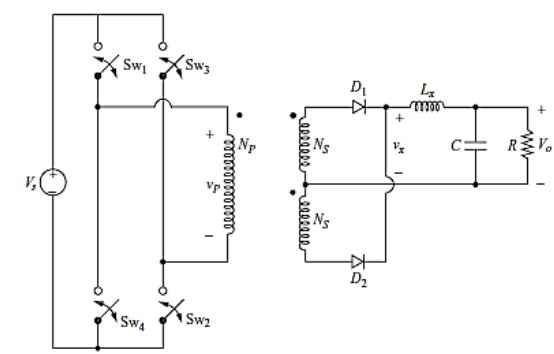

Full bridge 